\title{
Serum Prolactin in Patients with Rheumatoid Arthritis and its Association with Disease Activity
}

\author{
Dalia M. Fayez, Reem A. Habeeb, Sameh A. Hassan, Noha H. Abdelfatah \\ Department of Internal Medicine, Ain Shams University; Egypt
}

\begin{abstract}
Background: Rheumatoid arthritis is a systemic autoimmune disease characterized by inflammatory polyarthritis. Prolactin acts as a potent immunomodulator and may play a role in disease severity and the process of joint damage in Rheumatoid arthritis. Aim of Study: The aim of this study was to evaluate the level of serum prolactin in patients with Rheumatoid arthritis and determine its association with disease activity and structural damage. Patients and Methods: The study included 40 patients with Rheumatoid arthritis and 20 healthy individuals as controls. All patients were subjected to clinical and immunological evaluation and assessment of disease activity using the DAS 28 score. Plain X-ray of both hands and feet were done for joint damage assessment by using SENS score. Results: Serum prolactin concentrations in patients were significantly higher (Mean \pm SD 11.9 \pm 7.30$)$ than controls $($ Mean \pm SD $6.92 \pm 3.62)(P-v a l u e ~<0.05)$. Higher level of serum prolactin was detected in patients with severe disease activity by DAS-28 score (Mean \pm SD $=13.77 \pm 7.288)$ compared to patients with moderate (Mean $\pm \mathrm{SD}=5.89 \pm 1.03$ ) and low disease activity $(\mathrm{Mean} \pm \mathrm{SD}=4.25 \pm 0.35)(\mathrm{p}$-value $=0.008)$. Serum prolactin levels significantly correlated with DAS-28score $(\mathrm{p}$-value $=0.000)$. Conclusion: Serum prolactin increases in Rheumatoid arthritis patients and higher levels are associated with severe disease activity, however further studies with larger number of patients is still needed to establish the exact role of prolactin in the pathogenesis of Rheumatoid arthritis. [Egypt J Rheumatology \& Clinical Immunology, 2015; 3(1): 55-60]
\end{abstract}

Key Words: Rheumatoid arthritis, Disease activity, Prolactin.

\section{INTRODUCTION}

Rheumatoid arthritis (RA) is a systemic autoimmune disease characterized by inflammatory polyarthritis. The hallmark of RA is symmetric synovial proliferation and tenderness of multiple joints, particularly the small joints of the hands and feet ${ }^{1}$

Prolactin receptors (PRL-Rs) are members of the cytokine receptor super-family. Several isoforms of PRLRs have been described based on the differences in the amino acid sequence and size of the cytoplasmic domain; PRL-Rs are expressed on monocytes, macrophages, T and mainly B-lymphocytes, natural killer (NK) cells, granulocytes and thymus epithelial cells ${ }^{2}$

In addition to its unique roles in reproduction and lactation, PRL acts as a potent immunomodulator. The immune capability of PRL is generally stimulatory, while oestrogens and cortisol support the anti-inflammatory Th2 immune response. PRL maintains immune homeostasis, and its receptors have been detected on several immune cells, synovial fibroblasts and chondrocytes, In immune cells, PRL up regulates transcription of the interferon regulatory factor IRF-1 gene and modulates expression of proinflammatory cytokines interleukin (IL)-12, interferon (IFN) $\alpha$ and tumor necrosis factor (TNF) $\infty$, . Moreover, For Correspondence: fm_dalia@hotmail.com
PRL exhibits anti-apoptotic activities, leading to increased survival of both auto reactive T cells and Bcells ${ }^{3}$

In some clinical trials, the level of PRL in serum was significantly higher in patients with RA, implicating that PRL may play a role in disease severity and the process of joint damage in RA and contributes to the development of the disease; In some studies PLR level was higher with longer disease evolution and worse functional condition ${ }^{2}$

\section{Aim of The Work:}

The aim of this study was to evaluate the level of serum prolactin in patients with rheumatoid arthritis and determine its association with disease activity and structural damage.

\section{SUBJECTS AND METHODS}

This study included 2 Groups: Group A: 40 RA patients classified according to new EULAR/ACR classification criteria for RA diagnosis ${ }^{4}$ and Group B: 20 age and sex matched apparently healthy subjects. Patients were recruited from the Rheumatology Outpatient Clinic and Rheumatology inpatient department at Ain Shams University Hospital. The nature of this study was explained to all participants. 
The laboratory and radiological procedures represented the standard care and posed no ethical conflicts. Verbal consent was obtained from all participants.

\section{All patients were subjected to the following:}

* Detailed history taking and full clinical and musculoskeletal examination with Assessment of disease activity state using DAS 28 score (ESR): Assessment of disease activity state using DAS 28 score ( ESR )was divided into , remission $(\leq 2.6)$, mild disease activity $(>2.6 \leq 3.2)$, moderate disease activity $(>3.2 \leq 5.1)$, severe disease activity $(>5.1)^{5}$

* Laboratory investigations including:

- Complete blood picture (CBC), erythrocyte sedimentation rate (ESR), quantitative Creactive protein (CRP).

- $\quad$ Routine liver and kidney function tests.

- $\quad$ Rheumatoid factor (RF) titer and level of serum anti-citrullinated peptide autoantibodies (anti CCP)

- The determination of PRL concentrations in the serum were performed by ELISA in an ES-700 instrument (Boeh-ringerMannheim) and the results was expressed in $\mathrm{ng} / \mathrm{ml}$; international standard is $20 \mathrm{ng} / \mathrm{ml}$ in men and $25 \mathrm{ng} / \mathrm{ml}$ in women.

* Radiological evaluation; Plain x-ray of both hands and feet for joint damage assessment by using SENS score (simple erosion narrowing score) ${ }^{6}$

\section{Statistical Methods}

Analysis of data was done by IBM computer using SPSS (statistical program for social science version 12) as follows: Description of quantitative variables as mean, SD and range. Description of qualitative variables as number and percentage. Chi square test was used to compare qualitative variables between groups. Spearman correlation test was used to rank different variables against each other positively or inversely. Unpaired t- test was used to compare quantitative variables, in parametric data $(\mathrm{SD}>50 \%$ mean). One way ANOVA was used to compare between more than three groups with parametric data. For all data $\mathrm{P}$ value $>0.05$ was insignificant, $\mathrm{P}<0.05$ was significant and $\mathrm{P}<0.01$ was highly significant.

\section{RESULTS}

The study was conducted on sixty participants. They were divided into two groups: Group I which represents 40 RA patients, $20(50 \%)$ were females and $20(50 \%)$ were males, their age ranged from 28 to 65 years, with Mean age (46.85 \pm 9.73$)$ years and mean duration of disease ranged from 2-17 years, with Mean duration $(8.1 \pm 3.46)$ years. Group II which represents 20 age and sex matched healthy volunteers as a control group, $10(50 \%)$ were females and $10(50 \%)$ were males, their age ranged from 23 to 70 years, with mean age $(41.4 \pm 14.33)$ years.

Table 1. Clinical data of Group I.

\begin{tabular}{|c|c|c|}
\hline Variables & N. & $\%$ \\
\hline Morning stiffness & 23 & 57 \\
\hline Arthralgia & 35 & 87 \\
\hline Arthritis & 13 & 32 \\
\hline Rheumatoid nodules & 5 & 12 \\
\hline lung manifestation & 0 & 0 \\
\hline renal manifestation & 0 & 0 \\
\hline cardiac manifestation & 0 & 0 \\
\hline muscle weakness & 28 & 70 \\
\hline cutaneous manifestation & 0 & 0 \\
\hline ocular manifestation & 0 & 0 \\
\hline carpal tunnel syndrome & 9 & 23 \\
\hline
\end{tabular}


Table 2. Laboratory data of Group I.

\begin{tabular}{lccc}
\hline \multicolumn{1}{c}{ Variables } & Minimum & Maximum & Mean \pm SD \\
\hline Hct mg\% & 25 & 48 & $36.33 \pm 3.03$ \\
Tlc*1000 mg\% & 4 & 14.3 & $7.72 \pm 2.74$ \\
Plat.*1000 mg\% & 130 & 420 & $276.22 \pm 80.59$ \\
Hb g\% & 7.3 & 15.5 & $12.50 \pm 1.38$ \\
ESR(mm/h) & 16 & 125 & $63.75 \pm 25.18$ \\
CRP(Qua.)(mg/dl) & 8 & 48 & $24.35 \pm 13.07$ \\
RF(Titer)(Iu/ml) & 9 & 95 & $39.80 \pm 24.76$ \\
Anti-CCP(Iu/ml) & 11 & 76 & $41.18 \pm 21.12$ \\
S.Prolactin(ng/dl). & 4 & 40 & $11.91 \pm 7.30$ \\
\hline
\end{tabular}

Table 3. Disease activity in Group I (according to DAS score)

\begin{tabular}{lcc}
\hline \multicolumn{1}{c}{ DAS-28 } & $\mathbf{N}=\mathbf{4 0}$ & $\mathbf{\%}$ \\
\hline Remission $(\leq 2.6)$ & 0 & $0 \%$ \\
Mild Disease Activity $(>2.6 \leq 3.2)$ & 3 & $7.5 \%$ \\
Moderate Disease Activity $(>3.2 \leq 5.1)$ & 6 & $15 \%$ \\
Severe Disease Activity $(>5.1)$ & 31 & $77.5 \%$ \\
\hline
\end{tabular}

Table 4. Radiological SENS score of Group I.

\begin{tabular}{lccc}
\hline & Minimum & Maximum & Mean \pm SD \\
\hline SENS/86 & 4 & 50 & $31.05 \pm 10.67$ \\
\hline
\end{tabular}

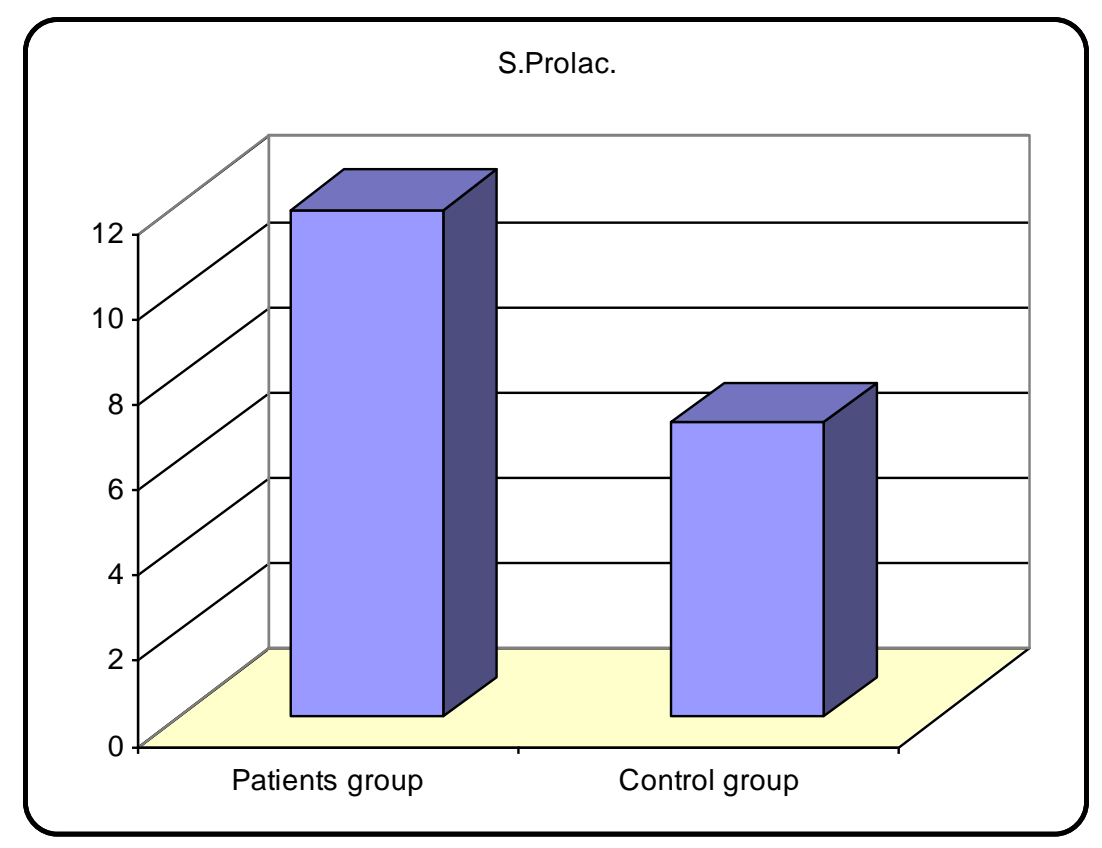

Figure 1. Comparison between Group I and Group II regarding serum prolactin. 


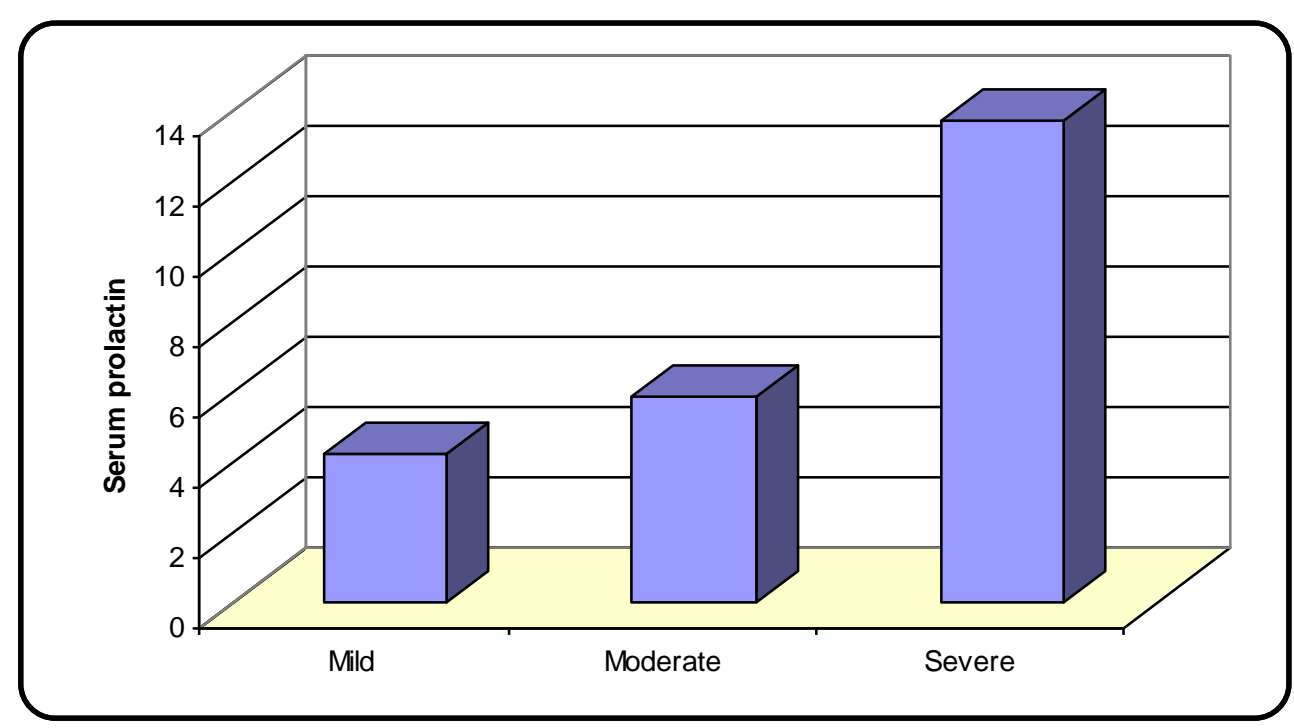

Figure 2. Comparison between patients with mild, moderate and severe disease activity regarding serum prolactin.

Table 5. Correlation between serum prolactin and various parameters in the Group I.

\begin{tabular}{lcc}
\hline & \multicolumn{2}{c}{ Serum Prolactin. } \\
\cline { 2 - 3 } & $\mathrm{r}$ & $\mathrm{p}$-value \\
\hline Age & -0.345 & 0.029 \\
Durat./ys & -0.212 & 0.189 \\
Hb & -0.077 & 0.637 \\
Hct & -0.022 & 0.893 \\
Tlc*1000 & -0.092 & 0.572 \\
Plat.*1000 & 0.788 & 0.000 \\
ESR & 0.345 & 0.029 \\
CRP (Qua.) & 0.439 & 0.005 \\
RF(Titer) & 0.220 & 0.173 \\
ACCP & -0.243 & 0.130 \\
DAS & 0.719 & 0.000 \\
SENS/86 & 0.772 & 0.000 \\
\hline
\end{tabular}

\section{DISCUSSION}

Rheumatoid arthritis (RA) is a chronic inflammatory disease that follows a slowly progressive destructive course. The most visible target of the inflammatory process is the synovial membrane, joint pain and swelling, and eventually irreversible damage to cartilage, tendons, and bones dominate the clinical presentation.

The role of prolactin (PRL) in the immune response was demonstrated for the first time in 1972. PRL is a hormone with cytokine like activities that has been proven to be involved in immune responses. It has been suggested that prolactin may have a pathogenic role in RA patients, since in vitro studies have shown that prolactin enhances inflammatory responses. Furthermore, dopamine agonists, which suppress pituitary secretion of prolactin may be useful adjunct to treatment in patients with $\mathrm{RA}^{8}$

Multiple studies have been carried out to estimate serum prolactin levels in RA patients and compare it with normal healthy controls and to characterize its potential association with the disease activity and joint damage ${ }^{9}$

This study was carried out to measure the level of serum prolactin in RA patients and determine its association with disease activity and structural damage. 
The results of our study showed that the serum prolactin concentrations in RA patients were significantly higher (Mean \pm SD 11.9 \pm 7.30$)$ than controls (Mean \pm SD 6.92 \pm 3.62 ) (P-value $<0.05)$. This was in agreement with several studies that found raised serum prolactin levels in RA patients than controls. One study carried out on 90 RA patients found raised serum prolactin levels in RA patients (Mean $\pm \mathrm{SD}=20 \pm 9.30$ ) than controls (Mean $\pm \mathrm{SD}=14.62 \pm 6.62) \quad(p$-value $=0.003) .{ }^{10}$ Another study on 60 RA patients also found raised serum prolactin levels in RA patients (Mean $\pm \mathrm{SD}=$ 21.2 \pm 7.40$)$ than controls (Mean $\pm \mathrm{SD}=12.22 \pm 5.62)(\mathrm{p}-$ value $=0.038){ }^{8}$ Similarly another study also detected raised serum prolactin levels in RA patients (Mean $\pm \mathrm{SD}=$ $22 \pm 8.30)$ than controls $($ Mean $\pm \mathrm{SD}=11.42 \pm 4.62)(\mathrm{p}-$ value $=0.041)^{3}$

Clinical trials have stated that the level of serum PRL is significantly higher in patients with RA indicating that PRL may play a role in disease severity and the process of joint damage in RA and contribute to the development of the disease ${ }^{2}$

In contrast however to our study one study carried out on 30 RA patients and 10 controls found no elevation of serum prolactin levels in RA patients (Mean $\pm \mathrm{SD}=$ 17 \pm 5.30 ) compared with healthy controls (Mean \pm SD $=15 \pm 3)(\mathrm{p} \text {-value }>0.05)^{11}$

In the present study there was a higher level of serum prolactin concentration in patients with severe disease activity by DAS-28 score (Mean \pm SD $=13.77 \pm 7.288$ ) compared to patients with moderate (Mean \pm SD $=5.89 \pm 1.03)$ and low disease activity (Mean $\pm \mathrm{SD}=4.25 \pm 0.35)$ (p-value $=0.008)$, altogether serum prolactin levels significantly correlated with DAS28 score in RA patients ( $p$-value $=0.000$ ), which was in agreement with several studies which found a trend for the association between high serum prolactin levels and patients with severe disease activity (Mean $\pm \mathrm{SD}=$ $24.63 \pm 7.7)$ compared to patients with moderate and low disease activity $(\mathrm{Mean} \pm \mathrm{SD}=9.45 \pm 6.1)(\mathrm{p} \text {-value }=0.078)^{3}$

In addition there was a significant positive correlation between the measured serum PRL levels and ESR $($ Mean $\pm S D=63.75 \pm 25.18)(P$-value $=0.029)$ as well as $\mathrm{CRP}(\mathrm{Mean} \pm \mathrm{SD}=24.35 \pm 13.07)(\mathrm{P}$-value $=0.005)$ in RA, this was in agreement with other studies which stated that serum prolactin was increased in RA patients with active synovitis and high erythrocyte sedimentation rate $^{9}$

In contrast however one study carried out on 56 RA patients concluded that no correlation was found between serum prolactin level in RA patients and disease activity, serum rheumatoid factor or anti-CCP. ${ }^{12}$ Similarly another study carried out on 29 RA patients and 26 controls revealed no significant correlation between the serum prolactin level and the levels of serum CRP or with the serum autoantibodies such as IgM-RF or $\mathrm{ACCP}^{3}$
In this study there was a significant positive correlation between serum prolactin level and radiological finding by SENS score $(\mathrm{r}$ value $=0.772, \mathrm{p}$ value $=0.000$ ), this was in agreement with another study which found that radiological score showed positive significant correlation with the serum prolactin levels $(\mathrm{r}$ value $=0.484, p$ value $=0.014)^{3}$

In this study no significant correlation was detected between serum prolactin level and disease duration ( $\mathrm{r}$ value $=-0.212$, $\mathrm{p}$-value $=0.189$ ), which was in contrast to other studies which stated that that serum PRL levels correlated with the disease duration of RA $(\mathrm{p}=0.01)^{10}$

\section{Conclusion}

In this study serum prolactin level in RA patients was significantly higher than controls. Furthermore serum prolactin level was higher in RA patients with severe disease activity compared to patients with moderate and low disease activity. There was significant positive correlation between serum prolactin in RA patients and ESR, CRP, SENS/86.

It can be concluded from the present study that prolactin increases in RA patients and that higher levels are associated with severe disease activity, however further studies with larger number of patients is still needed to establish the exact role of prolactin in the pathogenesis of RA and weather anti-prolactin therapy could be of value in treatment of RA patients.

[Disclosure: Authors report no conflict of interest]

\section{REFERENGES}

1. Liao KP and Karlson EW: Classification and epidemiology rheumatoid arthritis text of rheumatology, 5th edition 2012; (2):796

2. Shelly S, Boaz M and Orbach H : Prolactin and autoimmunity. Autoimmunity Reviews 2012; 11, A465-A470

3. Fojtíková M, Studýnková JT, Filková $M$ et al. : Elevated prolactin levels in patients with rheumatoid arthritis, association with disease activity and structural damage. Clinical and Experimental Rheumatology; 2010, 28: 849-854.

4. Venables PJ and Maini RN: Diagnosis and differential diagnosis of rheumatoid arthritis. Retrieved 2014, May 19, 2014.

5. Ton E, Bakker M, Verstappen S et al. Look beyond the disease activit score of 28 joints (DAS28): Tender points influence the DAS28 in patients with rheumatoid arthritis. Journal of Rheumatology; 2012, 39:22-27.

6. Van der Heijde D, Dankert T, Nieman F et al. Reliability and senstivit to change of a simblification of the Sharp/van der Heijde radiological assessment in rheumatoid arthritis. Rheumatology; 1999, 38:941-947 
7. Singh K, Deshpande P Li G, Yu M, Pryshchep S et al. K-RAS GTPase-and B-RAF Kinase-mediated T-cell tolerance defects in rheumatoid arthritis. Proc Naltl Acad Sci USA, 2012; 19; 109(25):E1629-37.

8. Ram S, Blumberg D, Newton P. Raised serum prolactin in rheumatoid arthritis: genuine or laboratory artifact. Rheumatology 2004; 43:12721274.

9. Ghule S, Dhotre A, Gupta M. Serum prolactin levels in women with rheumatoid arthritis. Biomedical Research 2009; 20(1):115-118.
10. Mateo L, Notella JM: Prolactin in rheumatoid arthritis, received 4 january 1999 from www. stockton. Press co.uk/lup

11. Chuang E, Molitch M: Prolactin and autoimmune diseases in humans. ACTA BIOMED 2007, 78; Suppl 1:255-261

12. Orbach H, Goddard G, Amital HM Barak V et al. Novel biomarkers in autoimmune diseases, prolactin, ferritin, vitamin $\mathrm{D}$, and TPA levels in autoimmune diseases.Ann.N.Y.Acad.Sci. 2007, 1109: 385-400. 